\title{
FAKTOR PENTING PENINGKATAN DUKUNGAN DAN PARTISIPASI MASYARAKAT DESA PENYENGAT PADA KEGIATAN PERDAGANGAN KARBON KPHP TASIK BESAR SERKAP
}

\author{
Ervayenri, Emy Sadjati, Enny Insusanty \\ Staf Pengajar Fakultas Kehutanan Universitas Lancang Kuning \\ Jln. Yos Sudarso Km. 8 Rumbai Pekanbaru Riau \\ Email :ervayenri_jayaputra@yahoo.com; emymnhunilak@gmail.com; annovisa@yahoo.com
}

\begin{abstract}
This study aims to identify factors important to increase support and participation of village communities Penyengat on carbon trading in KPH Tasik Besar Serkap. The study was conducted from September 2015 until December 2015 involving 40 respondents in village of Penyengat Sungai Apit, Siak District, Riau Province. Data was collected through interviews using a structured questionnaire. The study states that all respondents (100\%) like to plant a tree. Types of trees planted by the respondents are fruits (33,33\%), corn (22,22\%), and forest plants (22,22\%). In addition to plant rubber trees, palm or other forest plants, the majority of respondents $(50,00 \%)$ to plant annual crops under the crop. Types of crops that are vegetables $(50,00 \%)$. The seasonal crops majority $(78,79 \%)$ and partly consumed by $(6,06 \%)$ were sold to consumers around the village Penyengat. Most respondents $(72,73 \%)$ had never heard of climate change / REDD+, only $15,15 \%$ of respondents who have heard through village officials (52,38\%) and the RT (14,29\%). Most respondents $(44,44 \%)$ did not know the meaning of REDD+ activities. If REDD+ activities are carried out, the potential of local institutions to implement is a farmer groups $(33,33 \%)$, and public $(33,33 \%)$. While other respondents $(22,22 \%)$ could not give an answer about local agencies that have the potential to implement carbon trading activities in the village Penyengat. If REDD + activities be conducted, the training needs to be done according to the respondents (71,43\%) for the institution designated as administrators. Institutions that may be involved is a farmer groups $(62,50 \%)$.
\end{abstract}

Keywords: carbon trading, increased support, REDD +

\section{PENDAHULUAN}

REDD pertama kali dicanangkan di COP 13 di Bali pada tahun 2007, dan telah menghasilkan Rencana Aksi Bali (Bali Action Plan) ide tersebut sangat diminati oleh negara-negara dengan laju deforestasi yang tinggi. Negara-negara tersebut memiliki po-tensi terbesar untuk secara signifikan mengurangi emisi dari hilangnya hutan dan untuk memperoleh ke-untungan jika mereka dapat melakukannya. Satu tahun setelah Ren-cana 
Aksi Bali disetujui, para juru runding mengadakan pertemuan kembali di Poznan, Polandia. Mereka mencapai konsensus umum bahwa kegiatan REDD sebaiknya diperluas. Pendekatan ini disebut dengan REDD-plus. Transfer finansial diba-wah REDD-plus tidak hanya digu-nakan untuk mengurangi deforestasi dan degradasi hutan, namun juga digunakan untuk melakukan konser-vasi cadangan karbon di hutan, pengelolaan hutan lestari dan peningkatan cadangan karbon hutan melalui kegiatan penanaman pohonpohon dan rehabilitasi lahan yang terdegradasi. Mekanisme ini memi-liki keuntungan dengan membuka kesempatan bagi berbagai pihak yang memiliki situasi nasional yang berbeda untuk dapat diikutsertakan dalam kerangka kerja di masa men-datang (Mardiatmoko, 2015).

Pada tahun 1997 World Resources Institute yang melakukan pemetaan hutan belantara di Suma-tera, dan menyatakan Hutan Produksi Tasik Besar Serkap merupakan salah satu dari empat hutan belantara yang sangat penting di Sumatera. Hutan Produksi Tasik Besar Serkap meru-pakan sisa hutan rawa gambut ter-besar Sumatera yang terletak di Pe-sisir Timur pulau
Sumatera. Hutan Produksi Tasik Besar Serkap meru-pakan salah satu dari delapan (8) blok kawasan yang memiliki nilai konsevasi tinggi (High Conservation Value Forest) di Propinsi Riau. Namun akibat aktivitas eksploitasi dan konversi/ alih fungsi terhadap hutan alam dikawasan ini, luasan tutupan hutan alam terus berkurang. Dalam pengembangannya, selanjut-nya areal ini ditetapkan Menteri Kehutanan sesuai Keputusan Nomor : SK.509/MenhutVII/2010 Tanggal 21 September 2010 yang menetap-kan Wilayah Kesatuan Pengelolaan Hutan Produksi (KPHP) Model Tasik Besar Serkap Kabupaten Pela-lawan dan Kabupaten Siak seluas 513.276 Ha. Dari luasan yang ada direncanakan untuk jasa lingkungan karbon adalah seluas 7.679,45 $\mathrm{Ha}$.

Pengembangan jasa lingkungan kar-bon harus memperoleh dukungan dari masyarakat sekitar hutan yang memiliki kaitan erat dan berinteraksi langsung dengan hutan. Peluang perdagangan karbon melalui mekanisme REDD+ menjadi salah satu bentuk upaya memperoleh manfaat dari hutan sebagai bentuk peman-faatan jasa lingkungan. Sementara dari masyarakat awam, perdagangan karbon belum dikenal secara baik sehingga 
perlu diketahui pemahaman dan persepsi serta faktor penting lainnya untuk meningkatkan dukung-an dan partisipasi masyarakat sekitar hutan terhadap perdagangan karbon.

\section{Tujuan}

Penelitian ini bertujuan untuk mengetahui faktor penting untuk meningkatkan dukungan dan partisipasi masyarakat Desa Penyengat terhadap perdagangan karbon di KPH Tasik Besar Serkap

\section{Manfaat}

Manfaat penelitian ini adalah mem-berikan informasi kepada pihak-pihak yang memiliki kepentingan terhadap kegiatan perdagangan karbon seperti pemerintah pusat dan daerah, unit manajemen di tingkat tapak (KPHP) serta masyarakat di sekitar kawasan yang dijadikan contoh areal kegiatan REDD+.

\section{METODE PENELITIAN}

\section{Waktu dan Lokasi Penelitian}

Penelitian ini dilakukan selama 4 bulan mulai bulan September 2015 sampai dengan Desember 2015 di Desa Penyengat Kecamatan Sungai Apit, Kabupaten Siak

\section{Metode}

Penelitian ini merupakan penelitian survei yang dilakukan untuk me-ngetahui pemahaman dan persepsi masyarakat dalam hubungannya dengan perdagangan karbon. Pengambilan sampel dilakukan secara acak sampling terhadap responden yang berada disekitar $\mathrm{KPH}$ Tasik Besar Serkap. Teknik pengumpulan data pada penelitian ini dilakukan dengan cara :

a. Wawancara terstruktur dan be-bas dengan bantuan kuisioner. Metode wawancara ini dapat digunakan hanya sebagai tool pengumpulan data bersama-sama instrumen yang lain (Irawan, 2007)

b. Pengamatan atau observasi lapangan untuk melihat langsung kondisi masyarakat dan kondisi lapangan

\section{Pengolahan dan Analisis Data}

Data yang telah diperoleh baik dari penelitian lapangan maupun penelitian kepustakaan akan diolah secara kualitatif dengan metode deskriptif.

\section{a. Kualitatif}

Yaitu metode analisis data yang mengelompokkan dan menyeleksi data yang diperoleh dari penelitian lapangan menurut kualitas dan kebenarannya, kemudian dihubung-kan dengan teoriteori yang diper-oleh dari studi kepustakaan sehingga diperoleh 
jawaban atas permasalahan yang diajukan.

\section{b. Deskriptif}

Yaitu metode analisis dengan me-milih data yang menggambarkan ke-adaan sebenarnya di lapangan. Da-lam analisis ini menggunakan cara berfikir induktif yaitu menyimpulkan hasil penelitian dari hal yang sifatnya khusus ke hal yang sifatnya umum.

\section{HASIL DAN PEMBAHASAN}

\section{Letak Geografis}

Desa Penyengat memiliki luas se-kitar $54.000 \mathrm{Ha}$ yang terbagi ke dalam tiga dusun, yakni Dusun I (Du-sun Penyengat), Dusun II (Dusun Tanjung Pal), dan Dusun III (Dusun Sungai Mungkal). Desa Penyengat memiliki batas-batas wilayah admi-nistratif, yakni sebelah utara ber-batasan dengan Laut Selat Panjang, sebelah selatan berbatasan dengan Desa Dayun, sebelah barat ber-batasan dengan Desa Rawa Mekar Jaya, dan sebelah timur berbatasan dengan Desa Teluk Lanus

Potensi Sumber Daya Karakteristik Responden
Desa Penyengat adalah hutan be-lantara tempat berburu babi, menjerat rusa, mengambil hasil hutan (kayu) untuk membuat rumah, dan meng-ambil hasil hutan non kayu seperti damar, rotan, ramuan obat tradisional untuk upacara sosial. Pada mulanya masyarakat suku asli Anak Rawa ini bermukim di pinggir Sungai Rawa, sehingga ketergantungan hidup masyarakat pada hutan, sungai dan laut adalah sangat tinggi

\section{Demografi}

Secara keseluruhan wilayah Desa Penyengat Kecamatan Sungai Apit Kabupaten Siak memiliki jumlah penduduk sebanyak 1.438 orang dengan jumlah laki-laki sebanyak 730 orang dan jumlah perempuan sebanyak 708 orang yang terdiri dari 350 Kepala Keluarga (KK). Dusun 1 (Desa Penyengat) memiliki jumlah penduduk sebanyak 517 orang dengan jumlah lakilaki sebanyak 268 orang dan jumlah perempuan sebanyak 249 orang dan terdiri dari 129 KK.

Tabel 1. Kelompok Umur Responden di desa Penyengat

\begin{tabular}{|cccc|}
\hline No & Umur (tahun) & Jumlah (orang) & Persentase (\%) \\
\hline 1 & $21-30$ & 6 & 15,00 \\
2 & $31-40$ & 15 & 37,50 \\
3 & $41-50$ & 11 & 27,50 \\
4 & $51-60$ & 4 & 10,00
\end{tabular}


5

$61-70$

4

10,00

Jumlah

40

100,00

Sebagian besar responden responden memiliki tingkat pendidikan berada pada kelompok umur 31 sd 40 dasar (67,50\%), bahkan ada yang tidak tahun $(37,50 \%)$, dan kelompok umur 41 bersekolah (5\%). Responden yang sd 50 tahun (27,50\%), sedangkan berpendidikan me-nengah sebesar sisanya berada dibawah 30 tahun (15\%) $22,50 \%$. Sedangkan responden yang dan diatas 50 taun sebanyak 20\%. berpendidikan ting-gi hanya sekitar 5,0\% Sementara itu sebagian besar

Tabel 2. Jenis Pekerjaan Responden di Desa Penyengat

\begin{tabular}{|c|c|c|c|}
\hline No & Jenis Pekerjaan & Jumlah (orang) & Persentase (\%) \\
\hline 1 & Karyawan & 1 & 2,50 \\
\hline 2 & IRT & 2 & 5,00 \\
\hline 3 & guru & 3 & 7,50 \\
\hline 4 & Buruh & 6 & 15,00 \\
\hline 5 & Nelayan & 6 & 15,00 \\
\hline 6 & Tukang & 4 & 10,00 \\
\hline 7 & Petani & 16 & 40,00 \\
\hline 8 & Pedagang & 2 & 5,00 \\
\hline & Jumlah & 40 & 100,00 \\
\hline
\end{tabular}

Sumber : Data Primer Diolah, 2015

Jenis pekerjaan responden yang guru (7,50\%), Ibu Rumah Tangga dan ter-banyak adalah petani (40,00\%). Se- pedagang (5\%) serta karyawan swasta lain itu juga terdapat profesi lain seperti (2,50\%). nelayan dan buruh (15\%), tukang (10\%),

Tabel 3. Kelompok Pendapatan Responden di Desa Penyengat

\begin{tabular}{cccr}
\hline No & Pendapatan (Rp/Bulan) & Jumlah (orang) & Persentase (\%) \\
\hline 1 & $<1.000 .000$ & 9 & 22,50 \\
2 & $1.000 .000-2.000 .000$ & 24 & 60,00 \\
3 & $>2.000 .000$ & 7 & 17,50 \\
\hline & Jumlah & 40 & 100,00
\end{tabular}

Sumber : Data Primer Diolah, 2015

Sebanyak 60,00\% responden 1.000 .000 sd Rp. 2.000 .000 per bu-lan. memi-liki pendapatan berkisar Rp. Sedangkan yang berpenghasil-an diatas 
Rp. 2.000 .000 perbulan mencapai $17,50 \%$. Sementara itu responden yang

Faktor Pendukung dan Partisipasi
Masyarakat Pada Kegiatan per-
dagangan Karbon Sebagian besar responden menyukai tanaman buah-buahan $(53,58 \%)$, ke-mudian tanaman sagu $(23,08 \%)$ dan tanaman hutan lainnya $(23,08 \%)$. Di desa Penyengat masyarakat paling banyak menanam pohon sagu $(33,33 \%)$, karet $(33,33 \%)$, sukun (16,67\%) dan sawit (16,67\%).

Selain menanam pohon karet, sawit atau tanaman hutan lain, sebagian responden $(50,00 \%)$ menanam tanaman semusim dibawah tanaman tersebut, sedangkan sebagian yang lain $(30,77 \%)$ tidak pernah mela-kukan penanaman tanaman semusim apapun. Jenis tanaman semusim yang ditanam adalah sayuran (50\%). Ta-naman semusim tersebut sebagian (78,79\%) dikonsumsi sendiri dan se-bagian lagi $(6,06 \%)$ dijual kepada para konsumen di sekitar desa Pe-nyengat. penghasilannya di-bawah Rp. 1.000 .000 mencapai $22,50 \%$.

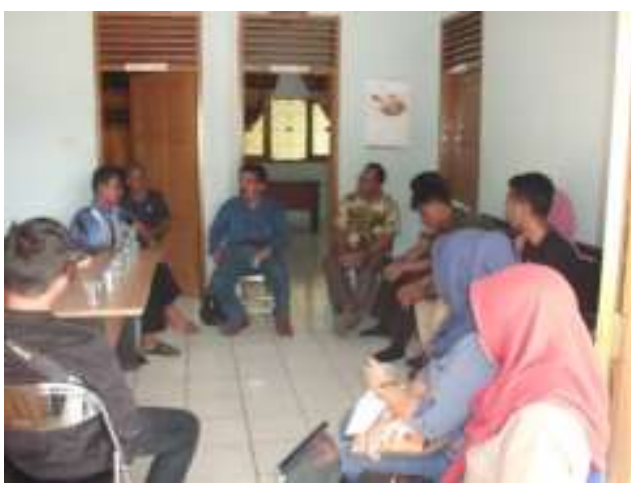

\section{Gambar 1. Wawancara dengan Aparat Desa di kantor Desa Penyengat.}

Sebagian besar responden $(72,73 \%)$ belum pernah mendengar tentang perubahan iklim/REDD+, hanya $15,15 \%$ responden yang per-nah mendengarnya melalui aparat desa $(52,38 \%)$ dan ketua RT (14,29\%). Sebagian besar responden (44,44\%) tidak mengetahui makna kegiatan REDD+ tersebut,

Dari hal diatas, terlihat bahwa penduduk desa Penyengat memiliki modal yang cukup untuk ikut membangun dan mengembangkan areal yang ada di sekitar desanya untuk kegiatan perdagangan karbon, karena kesadaran untuk selalu menanam dan menjaga pohon-pohon yang sudah ada serta yang akan ditanam di masa yang akan datang cukup tinggi. Hanya karena keter-batasan pengetahuan yang berimbas pada pemahaman tentang 
perda-gangan karbon, sehingga mereka tidak begitu memahami detail teknis yang terjadi dalam mekanisme perdagangan karbon. Hal ini juga bisa dipahami karena sebagian besar responden berpendidikan sekolah dasar $(65 \%)$, hanya $5 \%$ saja yang berpendidikan tinggi, sehingga masih perlu pemahaman dan penyuluhan yang rutin kepada masyarakat desa Penyengat tentang mekanisme perdagangan karbon yang benar.

Sebagian besar responden (56,25\%) menyatakan kegiatan penanaman pohon yang dilakukan oleh kelompok tertentu cukup baik, se-bagian responden $(12,50 \%)$ ke-beratan dengan kegiatan tersebut, dan 18,75\% responden menyatakan mengetahui adanya kegiatan terse-but. Sebagian responden $(85,71 \%)$ menyatakan adanya hambatan dalam kegiatan tersebut, sedangkan 14,29\% responden menyatakan ketidakta-huannya. Menurut responden ham-batan terbesar datang terutama dari masyarakat (83,33\%). Menurut res-ponden hambatan tersebut bisa dicegah melalui dialog dengan pe-merintah (77,78\%).

Jika kegiatan REDD+ tersebut dilaksanakan maka institusi lokal yang potensial melaksanakannya adalah kelompok tani (33,33\%), dan masyarakat umum (33,33\%). Sementara responden lain $(22,22 \%)$ tidak bisa memberikan jawaban tentang institusi lokal yang potensial dalam melaksanakan kegiatan per-dagangan karbon di desa Penyengat. Jika kegiatan REDD+ akan dilaku-kan, maka menurut responden perlu dilakukan pelatihan $(71,43 \%)$ untuk lembaga yang ditunjuk sebagai pe-laksananya. Lembaga yang mung-kin dilibatkan adalah kelompok tani $(62,50 \%)$, sementara itu jika ditanyakan responden tentang peran dan bagamana memilih ketua serta ben-tuk pengelolaannya sebagian besar responden (5,71\%) menjawab tidak tahu.

Dari hasil wawancara yang diuraikan diatas, terlihat bahwa masyarakat desa Penyengat masih belum bisa menentukan lembaga yang akan melakukan kegiatan perdagangan kar-bon di desa mereka, seandainya hal tersebut akan dilaksanakan. Tetapi masyarakat desa tersebut mem-berikan rekomendasi tentang lemba-ga yang mungkin dianggap mampu melaksanakan kegiatan tersebut. Lembaga tersebut adalah Kelompok Tani. Untuk melibatkan secara pe-nuh, masyarakat memberikan saran agar 
dalam pelaksa-naannya perlu dilakukan pelatihan terutama yang berhubungan dengan organisasi dan tata kelola perdagangan karbon, sehingga masyarakat lebih siap dalam menjalankan kegiatan tersebut di masa yang akan datang.

\section{KESIMPULAN DAN SARAN}

\section{Kesimpulan}

Penduduk desa Penyengat memiliki modal yang cukup untuk ikut membangun dan mengembangkan areal yang ada di sekitar desanya untuk kegiatan perdagangan karbon, karena kesadaran untuk selalu menanam dan menjaga pohon-pohon yang sudah ada serta yang akan ditanam di masa yang akan datang cukup tinggi.

Masyarakat desa Penyengat memberikan rekomendasi Kelompok tani sebagai lembaga yang bisa menjalankan kegiatan perdagangan kar-bon di desanya. Tetapi dalam pelasanaannya perlu dilakukan pela-tihan terutama yang berhubungan de-ngan organisasi dan tata kelola per-dagangan karbon, sehingga masya-rakat lebih siap dalam menjalankan kegiatan tersebut di masa yang akan datang.

\section{Saran}

Perlu dilakukan inventarisasi dan identifikasi yang berhubungan dengan kelembagaan dan tata kelola yang lebih sederhana untuk masyarakat desa dalam kegiatan perdagangan karbon, sehingga bisa lebih imple-mentatif bagi pihak-pihak yang akan memanfaatkannya

\section{DAFTAR PUSTAKA}

Arief. A. 1994. Hutan: Hakikat dan Pengaruhnya Lingkungan terhadap

Burhan, A.2001. Metode Penelitian Hukum, PT Asdi Maha-satya, Jakarta.

Calhoun dan Acocella. 1990. Psikologi Tentang Penye-suaian dan Hubungan Ke-manusiaan.Edisi ketiga. Terjemahan. IKIP Semarang Press. Semarang

Departemen Pendidikan dan Kebudayaan Republik Indonesia. 1988. Kamus Besar Bahasa Indonesia, Balai Pustaka Jakarta.

Effendi, E. 2009. Moratorium Pemanfaatan Hutan Butuh $\mathrm{Rp}$ 75,24 T. Harian Ekonomi Neraca.

www.greenconomics.org Februari 2015]

Gunawan, Wawan. 1999. Persepsi dan Perilaku Sosial Eko-nomi Masyarakat Desa Sir-narasa Terhadap Pelestarian Sumberdaya Hutan di Ta-man Nasional Gunung Ha-limun. 
Skripsi. Jurusan Konservasi Sumberdaya Hutan, Fakultas Kehutanan Institut Pertanian Bogor

Harihanto.2001. Persepsi, Sikap dan Perilaku Masyarakat Terha-dap Air Sungai. Disertasi. Pasca Sarjana, Institut Per-tanian Bogor.

Johnny, I. 2006. Teori dan Metode Penelitian Hukum Norma-tif, Bayumedia Publishing, Malang,

Kartono, K dan D. Gulo. 1997. Ka-mus Psikologi. Pioner Jaya, Bandung

Rhamdani, H.S. 2011. Studi Sosial Ekonomi dan Persepsi Masyarakat Terhadap Corp-orate Social Responsibility (CSR) Perusahaan Hutan Tanaman Industri PT Nityasa Idola di Kalimantan Barat. Skripsi. Departemen Manajemen Hu-tan, Fakultas Kehutanan Institut Pertanian Bogor.

Ronny H.S, 1990. Metodologi Pe-nelitian Hukum, Ghalia, Jakarta,

Sarwono, S.W.2002. Psikologi Sosial Individu dan Teori-Teori Psikologi Sosial. Balai Pustaka, Jakarta.

Soerianegara, I dan A. Indra-wan.1998. Ekologi Hutan Indonesia. Departemen Ma-najemen Hutan. Fakultas Kehutanan. IPB.

Walgito, B. 2002. Psikologi sosial : Suatu Pengantar. Yogyakarta. Andi Offset. 